\title{
O trabalho das docentes da Educação Infantil e o mal-estar docente: o impacto dos aspectos psicossociais no adoecimento*
}

\author{
Maria de Fátima Duarte Martins ${ }^{1}$, Jarbas Santos Vieira ${ }^{2}$, \\ José Roberto Feijó ${ }^{3}$ e Vanessa Bugs ${ }^{4}$ \\ Universidade Federal de Pelotas (Capão do Leão, RS)
}

O estudo analisa a relação entre processo de trabalho e a saúde de 196 professoras das Escolas Municipais de Educação Infantil em uma cidade de porte médio no Rio Grande do Sul. O estudo foi dividido em duas etapas: qualitativa e quantitativa. Neste artigo, apresentamos resultados preliminares da etapa qualitativa. O questionário Job Content Questionnaire (Karasek, 2008) foi utilizado para captar as relações entre as demandas advindas do trabalho dessas professoras e o grau de controle que possuem sobre o mesmo, assim como verificar o suporte social recebido. Aqui, o foco são os aspectos psicossociais do trabalho e sua relação com o adoecimento. Os resultados revelaram que um grupo significativo de professoras está em risco de adoecimento, trabalhando em um ambiente que exige um alto grau de envolvimento, possuindo pouco controle sobre esse trabalho. A interação entre o trabalho e o ambiente laboral, a satisfação no trabalho e as condições de organização em que essas professoras exercem seus ofícios, da forma como estão, podem levá-las ao mal-estar docente.

Palavras-chave: Trabalho docente, Educação infantil, Demanda psicológica, Controle.

The work kindergarten teachers and the teacher malaise: the impact of psychosocial factors in disease

The study analyzes the relationship between labor process and illness in 196 teachers of Municipal Schools of Early Childhood Education in a medium-sized city in Rio Grande do Sul, Brazil. The study was divided into two stages: qualitative and quantitative. In this article, we present preliminary results of the qualitative stage. The Job Content Questionnaire (Karasek, 2008) was used to capture the relationship between the demands arising from work of these teachers and the degree of control they have over it, as well as checking the social support received. Here the focus is the psychosocial aspects of work and its relationship with illness. The results revealed that a significant group of teachers is at risk of illness, working in an environment that requires a high degree of involvement, having little control over this work. The interaction between work and the work environment, job satisfaction and conditions of the organization in which these teachers exercise their functions, the way they are, can expose them to teacher malaise.

Keywords: Teaching work, Child education, Psychological demand, Control.

\section{Introdução}

\footnotetext{
A partir da década 1990, no Brasil, o debate sobre o trabalho docente vem sendo redimensionado na perspectiva de analisar a produção de controle inspirada pelos novos modelos de gestão empresarial (Garcia \& Anadon, 2009; Moreira Hypólito, Vieira, \& Garcia, 2002). A penetração e relativa aceitação desses modelos por parte de governos e gestores escolares se devem a todo um cenário construído pelo neoliberalismo. E, mesmo que esses modelos de gestão não sejam aplicados em todas as dimensões da organização escolar e dos sistemas de ensino, têm inspirado diversos governos e escolas na produção de suas políticas para a educação.

Os professores estão implicados diretamente na viabilização dessa política e, por isso, o controle de seu processo de trabalho torna-se central para o alinhamento da educação às demandas

* Pesquisa financiada com recursos do Conselho Nacional de Desenvolvimento Científico e Tecnológico - CNPq - Edital MCT/ CNPq/MEC/CAPES N $~ 002 / 2010$

1 Faculdade de Educação - Departamento de Fundamentos da Educação - Programa de Pós Graduação em Ensino de Ciências e Matemática.

2 Faculdade de Educação - Departamento de Fundamentos da Educação - Programa de Pós Graduação em Educação.

3 Faculdade de Educação - Doutorando do Programa de Pós Graduação em Educação.

4 Faculdade de Educação - Programa de Pós Graduação em Educação.
} 
de trabalho. O conceito de controle, pelo menos nas duas últimas décadas, começou a tornarse central para a compreensão do trabalho docente e, por conseguinte, para a compreensão da produção e distribuição do conhecimento escolar. A organização do trabalho educativo torna-se, assim, objeto de reengenharia pelos homens de negócio e seus intelectuais (Vieira, 2004).

De uma forma ou de outra, esse controle interpelador acaba atingindo professores e professoras, ferindo sua autonomia e sua capacidade de concepção e, no limite, podendo atingir sua integridade física e emocional e levar ao adoecimento. O excesso de demandas distintas, e, muitas vezes, contraditórias (burocráticas, morais, pessoais, profissionais, técnicas etc.) somado à jornada extenuante e às precárias condições de trabalho, baixos salários, atividades e responsabilidades fundamentadas em um discurso profissional e ético comprometido com a formação dos sujeitos sociais atendidos pelas escolas públicas podem contribuir para a produção do mal-estar docente, quando as solicitações do ambiente excedem a capacidade de lidar com elas.

No ano de 1987, o psicólogo espanhol José Esteve (1999) cunhou a expressão "mal-estar docente" para descrever os efeitos permanentes que afetam negativamente as características pessoais e profissionais do professor como resultado das condições psicológicas e sociais em que exerce a docência. Paralelo aos estudos de Esteve, pesquisas sobre a relação entre o processo de trabalho e adoecimento começaram a ter relevância quando se elevaram consideravelmente o número de afastamentos de professores da sala de aula por motivo de doença (Araújo, 2008; Carlotto, 2004; Delcor, 2004; Gasparini, 2005; Paschoalino, 2009; Pereira, 2009).

$\mathrm{Na}$ cidade de Pelotas (RS), foi realizada uma pesquisa com todos os docentes da rede municipal (Vieira, Garcia, \& Martins 2010) que teve como um dos objetivos analisar o processo de trabalho docente e a repercussão sobre a saúde de todas as professoras e professores da rede pública municipal. Os resultados desse estudo demonstraram que as professoras da Educação Infantil foram as que mais solicitaram licença de saúde, sendo que problemas mentais aparecem em primeiro lugar, seguido de problemas comportamentais e doenças do sistema osteomuscular.

A partir desses resultados foi realizada uma nova pesquisa com intuito de mergulhar no universo das professoras de crianças pequenas, tentando estabelecer relações com as questões de saúde e de seu trabalho (A produção do mal-estar docente nas escolas municipais de educação infantil de Pelotas - Edital MCT/CNPq/MEC/CAPES № 02/2010).

Uma década depois de a Educação Infantil ser transformada em política pública, e quatro anos após a criação do Fundo de Manutenção e Desenvolvimento da Educação Básica e de Valorização dos Profissionais da Educação (Fundeb), em 2006, se faz necessário um balanço de seus efeitos sobre a Educação Infantil, em especial naquilo que pode ter relação com o processo de trabalho docente e, mais particularmente - de forma mediata -, com a saúde de suas professoras, tendo como campo privilegiado uma das maiores redes de escolas públicas municipais do Brasil, como é o caso da cidade de Pelotas.

Os resultados que ora apresentamos referem-se à etapa quantitativa da pesquisa.

\section{Educação infantil no Brasil: um fato relativamente novo}

Ser professora da Educação Infantil no Brasil é um acontecimento relativamente novo. As creches foram substituídas pelas escolas de Educação infantil, pois precisaram se adequar a um conjunto de novas exigências, entre elas a integração ao sistema de ensino básico até o ano de 1999. Na cidade de Pelotas (RS), local deste estudo, as Escolas Municipais de Educação Infantil foram criadas através do Decreto 4003/1999. As creches passaram a seguir as normas para a Educação Infantil estabelecidas pelo Conselho Estadual de Educação do Rio Grande do Sul através da Resolução no 246/1999. 
Foi a partir do Primeiro Congresso Brasileiro de Proteção à Infância, realizado em 1922, na cidade do Rio de Janeiro, que surgiram as primeiras regulamentações da prestação de atendimento às crianças pequenas das escolas maternais e jardins de infância, ainda com forte traço assistencialista (Venzke, 2004). Durante o primeiro governo de Vargas (1930-1945), os benefícios concedidos demonstravam que a maior preocupação do governo não era para com a criança, e sim com a força de trabalho feminina, que não podia faltar ao trabalho e comprometer os ganhos empresariais, necessitando de um lugar para deixar suas crianças. Na década de 1940, o atendimento nas creches voltava-se principalmente para as questões de saúde. A preocupação era com a alimentação, segurança física e higiene, não havendo um trabalho que se voltasse para o desenvolvimento intelectual e afetivo da criança.

Nos anos 1950, organizações intergovernamentais, tais como a Organização das Nações Unidas para a Educação, a Ciência e a Cultura (Unesco) e o Fundo das Nações Unidas para a Infância (Unicef), "influenciaram na nova proposta brasileira para o atendimento pré-escolar, que visava ao trabalho de assistência às crianças pobres. Começava, então, a surgir no Brasil o modelo de uma pré-escola de massa" (Venzke, 2004, p. 42). Nos anos 1990, a Lei de Diretrizes e Bases da Educação Nacional (Lei no 9.394/96) regulamenta a Educação Infantil, definindo-a como primeira etapa da Educação Básica e indicando como sua finalidade o desenvolvimento integral da criança de zero a seis anos de idade, em seus aspectos físico, psicológico, intelectual e social, de forma a complementar a ação da família e da comunidade.

A nova lei complementou a formação das professoras da Educação Infantil exigindo formação específica, o que gerou conflitos pelo fato de que muitas professoras não possuíam instrução ou, se possuíam, tinham como referência a Educação Fundamental. Entretanto, a norma deveria ser cumprida, e as Faculdades de Pedagogia assumiram a formação das professoras para atuarem nessa modalidade de ensino.

Apesar de criadas com o intuito de melhorar o ensino e o cuidado com as crianças pequenas, o que se tem observado é que essas professoras têm uma sobrecarga de responsabilidade pela qualidade do atendimento. $\mathrm{O}$ trabalho em condições precárias, e o alto índice de rotatividade devido à desvalorização profissional, assim como a falta de demarcação clara entre as atividades de mulher, mãe e professora e o desprestígio por serem frequentemente remetidas à figura de babá podem ser fatores para o mal-estar docente nas professoras da Educação Infantil.

Com o objetivo de conhecer o impacto do ambiente de trabalho na saúde das professoras da Educação Infantil, realizou-se um recorte nos resultados obtidos por meio da aplicação e análise do Job Content Questionnnaire (Karasek, 1985) como resultado da etapa quantitativa do estudo. Analisaramse os aspectos psicossociais avaliados pelo instrumento, principalmente em relação às demandas psicológicas provenientes do trabalho e ao grau de controle que as docentes possuem sobre elas, de forma a captar as percepções e as experiências das professoras em relação ao seu trabalho. O estudo foi financiado pelo Conselho Nacional de Desenvolvimento Científico e Tecnológico (CNPq). A pesquisa foi avaliada e aprovada pelo Comitê de Ética em Pesquisa do Curso de Enfermagem da Universidade Federal de Pelotas e as recomendações da Resolução n. 196/96 foram criteriosamente seguidas.

\section{Método}

Trata-se de um estudo de caráter censitário e corte transversal, da qual participaram todas as professoras das 26 Escolas Municipais de Educação Infantil (EMEIS) da cidade de Pelotas (RS), Brasil, totalizando 196 professoras.

Os dados funcionais (tempo de magistério, carga horária, situação marital) foram fornecidos pela Secretaria de Administração. Os dados referentes ao número de licenças de saúde e as doenças 
mais frequentes foram cedidos pelo Serviço de Biometria Médica, órgão municipal encarregado da perícia médica e fornecimento de atestados para afastamento do trabalho.

A pesquisa está dividida em duas etapas - uma quantitativa e outra qualitativa. A etapa quantitativa avaliou as características psicossociais do trabalho, especialmente as demandas psicológicas advindas da atividade docente e o controle que a professora exerce sobre elas. Para esse fim, utilizou-se o Job Content Questionnaire (JCQ), desenvolvido por Karasek (1979) e validado e traduzido para o Português como Questionário sobre Conteúdo do Trabalho por Araújo (2008). O JCQ é um instrumento validado e utilizado em diversos países da Europa, na América do Norte e no Japão. A partir da validação para o Brasil surgiram estudos nacionais que se utilizam do questionário (Alves, 2013; Barbosa, 2010; Mello, 2013; Pereira, 2009).

Para a aplicação do instrumento os pesquisadores participaram de uma oficina realizada com a professora Dra. Tânia Araújo, na Universidade Estadual de Feira de Santana, em Feira de Santana (BA).

A versão utilizada é composta de 49 questões que contemplam dois aspectos psicossociais do trabalho: a demanda psicológica (psychological demand) e o controle do trabalho (decision latitude). A demanda psicológica é definida pela percepção do indivíduo sobre a intensidade com que é exigido ou solicitado pelas tarefas que deve realizar e sobre os conflitos existentes na relação de trabalho. O grau de controle é a capacidade do indivíduo de decidir sobre o seu trabalho, através do poder de tomar decisões e de desenvolver habilidades. O questionário também avalia o suporte social proveniente da chefia e dos colegas, demanda física e insegurança no emprego. $\mathrm{O}$ instrumento a partir das evidências produzidas e consolidação de seus pressupostos foi amplamente difundido, sendo atualmente um dos modelos mais usados em saúde ocupacional e em estudos que envolvam os aspectos psicossociais do trabalho e repercussões sobre a saúde. Questões sobre identificação da escola e outros dados relevantes para o estudo foram acrescentadas no cabeçalho do JCQ, seguindo orientação do criador do instrumento.

O modelo demanda-controle estabelece quatro situações laborais: 1) trabalho com baixa exigência (envolve baixa demanda psicológica e alto controle), 2) trabalho passivo (com baixa demanda psicológica e baixo controle); 3) trabalho ativo (alta demanda psicológica e alto controle); e 4) trabalho com alta exigência (alta demanda psicológica e baixo controle). Esse modelo sustenta a hipótese de que o trabalho realizado na situação de alta exigência, na qual o trabalhador tem uma alta demanda psicológica proveniente de seu trabalho e baixo controle sobre essa demanda, representa a condição de mais elevada exposição e riscos à saúde física e mental.

Para a criação do banco de dados e análise das variáveis coletadas utilizou-se o programa Statistical Package for Social Science (SPSS, para windows, versão 13.0).

O projeto foi aprovado pelo Comitê de Ética em Pesquisa Envolvendo Seres Humanos, da Universidade Federal de Pelotas (UFPel) e as recomendações da Resolução n196/96 foram criteriosamente seguidas.

Para a análise das variáveis independentes principais, controle e demanda, utilizaram-se os indicadores construídos a partir do agrupamento das variáveis do JCQ. Os indicadores construídos a partir dos somatórios dos valores dos escores obtidos para as questões relacionadas a controle foram categorizados em "grau de controle da professora sobre seu trabalho", nivelado por: baixo controle, médio-baixo, médio-alto e alto. Para a demanda psicológica advinda do trabalho foi criado um indicador a partir da somatória dos valores dos escores referentes às questões relacionadas à demanda, segundo o modelo de Karasek (1979).

\section{Resultados}

A população do estudo são as 196 professoras - 195 mulheres e um homem - que estão em sala de aula exercendo a função docente. As mulheres são a grande maioria representando $99 \%$ 
da população estudada. Desse grupo 56,6\% estavam casadas, 32,7\% eram solteiras e 6,6\% eram separadas. A idade variou de 22 a 61 anos, sendo a média, 38 anos de idade; 27,6\% das docentes tinham nível superior completo e $23 \%$ nível superior incompleto. $O$ tempo médio na profissão era de nove anos. A carga horária de todas as professoras é de 40 horas semanais, determinadas por lei.

Em relação aos aspectos psicossociais do trabalho (tabela 1), para este estudo avaliaram-se os que estavam relacionados ao controle da professora sobre seu próprio trabalho; a demanda psicológica envolvida na realização das tarefas; o apoio recebido das colegas e o apoio recebido pela direção da escola.

Quanto ao controle que a professora tem sobre o seu trabalho, os resultados demonstraram que as professoras da educação infantil em uma porcentagem bastante expressiva $(99,9 \%)$ afirmaram que seu trabalho envolve a aprendizagem de coisas novas. Sobre as tarefas repetidas, $71 \%$ responderam positivamente a essa questão. Um total de $89 \%$ das professoras apontaram que o trabalho na Educação Infantil exige alto nível de qualificação. Para um número expressivo $(99,5 \%)$ a profissão requer criatividade, enquanto para 176 (89,9\%), possibilita fazer tarefas diferentes.

Acerca da possibilidade de tomar decisão no trabalho, 66,3\% responderam que podem tomar decisões por contra própria. Do total do grupo, 160 (81\%) consideraram que sua opinião a respeito do seu trabalho é levada em conta. Por outro lado, um grupo de 36 (18,4\%) professoras considerou possuir pouca liberdade para decidir como realizar e organizar o seu cotidiano.

Em relação à dimensão sobre as demandas psicológicas provenientes do trabalho, 36,2\% das entrevistadas responderam que trabalham em um ritmo acelerado. Um grupo de $90 \%$ considerou que seu ofício requer que trabalhem muito. Quanto ao volume de trabalho, 70 (35,5\%) das professoras referiram excessivo volume de trabalho. O tempo para realizar as tarefas foi considerado suficiente por $128(65,3 \%)$ das respondentes, e $134(68,4 \%)$ relataram trabalhar com demandas conflitivas provocadas por outros colegas.

$\mathrm{Na}$ terceira dimensão, que se refere ao apoio recebido pelas colegas de trabalho, 91,3\% responderam que são amigáveis e $88,3 \%$ afirmaram que as colegas são colaborativas. No que corresponde à ajuda mútua, 154 professoras $(78,6 \%)$ afirmaram existir tal suporte, apontando, a partir das respostas, para uma rede colaborativa em suas atividades laborais.

Nas questões referentes ao apoio recebido das diretoras da escola, encontrou-se que para 168 professoras a diretora se preocupa com o bem estar da equipe e 169 afirmaram que a diretora escuta o que o seu grupo tem a dizer. Um número de 144 docentes considerou a diretora como colaborativa e 153 consideraram-na como bem sucedida ao promover o trabalho em equipe. Um grupo de 43 docentes considera-se exposto à hostilidade da diretora.

Após a coleta das informações e considerando para a análise o modelo demanda-controle, os resultados demonstram que as professoras que responderam a todas as questões do questionário apresentaram os seguintes resultados: 48 realizavam o trabalho sob baixa exigência e possuíam um alto grau de controle sobre o mesmo, estando no grupo de referência "protegidas de adoecimento". O mesmo número de professoras (48) trabalha sob baixa demanda e possui baixo controle sobre esse trabalho, enquanto, do total de professoras, 49 possuíam alta demanda e alto controle sobre seu trabalho, estando esses dois grupos no quadrante intermediário. Outras 36 docentes apresentaram baixo controle sobre seu trabalho e possuíam altas demandas advindas do mesmo, sendo consideradas como pertencentes ao grupo de risco de adoecimento (Martins, Vieira \& Bugs, 2013).

Os resultados aqui expostos referem-se ao universo das professoras da Educação Infantil Municipal (EMEI) de uma cidade de porte médio do Rio Grande do Sul. Foram analisados a partir dos resultados do Job content questionnarire (JCQ) o qual avalia os dados do momento atual e as causas. 
Tabela 1. Características psicossociais do trabalho referidas pelas professoras da Educação Infantil Municipal da Cidade de Pelotas (RS), 2012

\begin{tabular}{|l|c|c|}
\hline \multicolumn{1}{|c|}{ Características psicossociais do trabalho } & Sim & $\%$ \\
\hline & & \\
\hline Controle sobre o próprio trabalho (N=196) & & \\
\hline Indicadores de uso de habilidades & 194 & 99 \\
\hline Trabalho requer que aprenda coisas novas & 141 & 71,9 \\
\hline Trabalho envolve repetitividade & 175 & 89,2 \\
\hline Exigência de alto nível de qualificação & 195 & 99,5 \\
\hline Requer criatividade & 176 & 89,9 \\
\hline Possibilita fazer tarefas diferentes & & \\
\hline Indicadores de autoridade decisória & 130 & 66,3 \\
\hline Permite tomar decisões por conta própria & 160 & 81,6 \\
\hline O que você diz sobre seu trabalho é considerado & 36 & 18,4 \\
\hline Tem pouca liberdade para decidir como fazer o próprio trabalho & & \\
\hline Demandas psicológicas (N=196) & 71 & 36,2 \\
\hline Ritmo de trabalho acelerado & 177 & 90,3 \\
\hline Requer que trabalhe muito & 70 & 35,7 \\
\hline Volume excessivo de trabalho & 128 & 65,3 \\
\hline O tempo é suficiente para realizar as tarefas & 134 & 68,4 \\
\hline Trabalho com demandas conflitivas feitas por outros & & \\
\hline Apoio recebido pelos colegas de trabalho (N=196) & 179 & 91,3 \\
\hline Colegas de trabalho são amigáveis & 154 & 78,6 \\
\hline Colegas ajudam-se uns aos outros & 173 & 88,3 \\
\hline Colegas são colaborativos & 168 & 85,7 \\
\hline Apoio recebido pela direção (N=196) & 43 & 21,9 \\
\hline Diretora se preocupa com o bem estar da equipe & 144 & 73,5 \\
\hline Diretora presta atenção no que digo & 78,1 \\
\hline Estou exposta a hostilidade da diretora & & \\
\hline Diretora ajuda na realização do trabalho & & \\
\hline A diretora é bem sucedida na promoção do trabalho em equipe & & \\
\hline
\end{tabular}

\section{Discussão}

Apesar do crescimento do uso do Job Content Questionnaire, muitos aspectos ainda permanecem controversos no que se refere ao Modelo Demanda-Controle, como as questões referentes aos indicadores utilizados para medir controle e demanda e as possíveis relações existentes entre essas duas dimensões. Outras críticas referem-se à adoção de um modelo investigativo demasiadamente simplista para avaliar situações complexas, uma vez que incorpora apenas duas dimensões do mundo do trabalho (demanda e controle). Contudo, outros pesquisadores realçam esse aspecto como positivo, argumentando que, à medida em que se utiliza um conjunto de variáveis para medir essas dimensões, é possível distinguir os principais aspectos psicossociais no trabalho. $\mathrm{O}$ modelo, portanto, não se baseia em uma lista de fatores sem critério de determinação ou de relevância, mas, ao contrário, compreende a existência de hierarquia entre os elementos que organizam a vida no trabalho (Araújo, 2003).

$\mathrm{Na}$ segunda parte desta investigação serão avaliados os aspectos qualitativos e, para esse fim, será realizada uma entrevista semiestruturada com cada uma das professoras do estudo, a fim de capturar nas suas falas o que pode não ter sido abordado pelo questionário (JCQ). Ao complementar os resultados quantitativos com a entrevista, deseja-se aumentar a confiabilidade e relevância do estudo.

As professoras das Escolas de Educação Infantil desse estudo realizam um trabalho em condições que podem não ser favoráveis à saúde principalmente pelo elevado nível de demanda 
psicológica, traduzida em tarefas que exigem excessiva, concentração, atenção, responsabilidade, paciência, compreensão, inclusive esforço físico quando seguram bebes de oito quilos ou mais. Somada a esses fatores o excesso de burocracia, os baixos salários, a carga horária de 40 horas semanais sem contar o trabalho realizado em casa e a falta de autonomia, representadas pelo baixo controle sobre seu trabalho podem ser geradores de adoecimento.

Embora o trabalho com crianças pequenas exija alta demanda emocional, as professoras referem-se ao seu ofício como criativo, envolvendo aprendizagens novas. Para algumas professoras, o trabalho é repetitivo, talvez pelas rotinas das Escolas de Educação Infantil orientadas pelos Projetos Pedagógicos e pelos Parâmetros Curriculares Nacionais para a Educação Infantil que determinam as práticas pedagógicas e sugerem conteúdos a serem desenvolvidos.

Em relação ao controle que possuem sobre seu próprio trabalho, os resultados são predominantemente positivos. A maioria afirmou ter autonomia para tomar decisões e suas tarefas são reconhecidas pelo grupo e direção, fatores importantes para a autoestima e que podem proteger de sentimentos de menos valia e depressão. Sobre a influência das demandas psicológicas, os resultados apontam para uma situação não tão favorável: um número expressivo declarou trabalhar muito e num ritmo acelerado, com risco para desenvolver estresse. O tempo disponível para realizar as tarefas foi considerado suficiente para algumas professoras.

O ambiente de trabalho foi apontado como amigável, a grande maioria das docentes encontra apoio nas colegas e essas são amigáveis e colaborativas. No que se refere ao apoio recebido da direção, os resultados são mais baixos embora ainda em nível de possibilitar um ambiente saudável; poucas referiram estar expostas a uma diretora hostil. $\mathrm{O}$ apoio das colegas e da diretora no cotidiano escolar pode servir como atenuadores dos problemas que podem aparecer na escola.

Ser professora de Educação Infantil no Brasil é relativamente novo. Enquanto anteriormente as creches eram responsáveis pelo atendimento às crianças, hoje a educação das crianças pequenas (zero a cinco anos) é reconhecida, havendo no Brasil uma Legislação que regulamenta sua prática. O reconhecimento dessa etapa de ensino como fundamental dentro da Educação Básica proporcionou avanços na sua qualidade, destacando-se, por exemplo, a exigência da formação pedagógica para ser educadora das crianças.

Os achados do estudo se referem especificamente às docentes entrevistadas, embora seus dados possam contribuir para outras pesquisas, assim como para ampliar as discussões sobre as políticas públicas voltadas para as crianças pequenas e suas professoras, pois a Educação Infantil é um desafio que o ensino público ainda enfrenta no Brasil.

Pesquisar as professoras de educação infantil a partir de seu universo possibilitou questionar verdades estabelecidas, problematizar o ser professora de crianças e suas especificidades, conversar sobre os mecanismos utilizados para atenuar as complexidades desse trabalho e sobre seus efeitos na saúde da profissional.

Muitas situações encontradas no cotidiano dessas professoras, tais como a sobrecarga de responsabilidade pela qualidade do atendimento das crianças pequenas, as condições precárias das escolas infantis, a desvalorização profissional que provoca um alto índice de rotatividade das professoras, resultando em falta de incentivo para permanência das docentes nessas escolas, a falta de demarcação clara entre as atividades de mulher, mãe e professora, as interpelações dos pais e o desprestígio por serem frequentemente remetidas à figura da babá, que não necessitaria de qualquer especialização para desempenhar seu trabalho, são aspectos estressantes relacionados ao trabalho. O baixo nível de autonomia e controle sobre o seu processo de trabalho, as jornadas longas e os múltiplos papeis assumidos pelas mulheres - considerando que o trabalho fora de casa não as desvincula de tarefas domésticas - e o ambiente de trabalho sem qualidade são fatores presentes na vida das professoras de educação infantil. 
Somados, esses problemas podem contribuir em grande parte para o processo de adoecimento dessas professoras. Entretanto, seria preciso analisar outras associações para que tal relação pudesse ser melhor compreendida, pois mesmo nas difíceis condições de trabalho são poucas as docentes que desejam abandonar o magistério.

As professoras que permanecem nas EMEIs por opção e buscam incessantemente a valorização profissional e social são mulheres que persistem na luta, apesar de inúmeras dificuldades. $O$ menor prestígio social que possuem por trabalharem em instituições ainda por muitos consideradas assistencialistas tem instigado algumas delas a seguir o caminho da superação. Entretanto, ao mesmo tempo em que se percebe em suas narrativas o compromisso com o cuidado e a educação de crianças pequenas, também estão sujeitas à acomodação e a momentos de desânimo causados, talvez, pela desvalorização salarial e pelas condições precárias de trabalho, potencializando o adoecimento de muitas delas.

\section{Conclusão}

Numa tentativa de conclusão, entende-se que, de acordo com Vieira et. al (2012), a Educação Infantil pode recair em algo como uma espécie de "Pedagogia do Adiamento": trabalhase com os alunos e as alunas hoje visando o seu amanhã, muitas vezes desconsiderando suas necessidades atuais. Assim, preocupa-se com a criança pensando em um vir a ser, e não em como ela é. Em outras palavras, existe uma espera por algo que não se consegue de imediato, e que somente em um futuro próximo ou distante será possível. Aguarda-se por um acontecimento que talvez não se realize e perde-se o que poderia ser vivido hoje. Essa expectativa adiada pode frustrar as professoras que não percebem a importância do momento atual, mas vislumbram um futuro para as crianças que provavelmente deixarão de acompanhar.

As professoras também são agentes na construção das Escolas de Educação Infantil, as quais se diferenciam das antigas Creches Municipais pela sua proposta de conciliar a educação e o cuidado de crianças pequenas, conforme a legislação em vigor. Assim, para que as escolas infantis do município tenham a qualidade necessária a atuação dessas profissionais possui uma significativa importância, tanto no que diz respeito à sua prática educativa e pedagógica quanto à melhoria das condições de trabalho por meio de reivindicações com o poder público municipal, o que ainda é uma conquista a ser realizada.

Em um artigo que apresenta uma revisão sistemática de estudos os quais avaliaram a exposição "estresse no trabalho" - de acordo com o modelo demanda-controle de Karasek- e utilizaram o JCQ, observa-se pelos resultados que não foi registrado estudo no Brasil abordando especificamente o grupo de professores da Educação Infantil (Alves, Hökerberg \& Faerstein, 2013).

Pesquisas nessa área são necessárias na medida em que contribuem para dar visibilidade ao trabalho das professoras da Educação Infantil, ofício que tem sido analisado e problematizado pela mídia e políticos os quais não fazem mais do que atribuir a culpa do fracasso escolar às professoras, sem conhecer a realidade enfrentada por essas mulheres que têm encontrado em medicamentos e licenças de saúde uma forma de aliviar a carga gerada pelo seu trabalho.

\section{Referências}

Alves, M. G., Hokerberg, Y. H., \& Faerstein, E. (2013). Tendências e diversidades na utilização empírica do Modelo Demanda-Controle de Karasek (estresse no trabalho): uma revisão sistemática. Rev. bras.epidemiol, 16:125136. 
Araújo, T. M., \& Karasek, R. (2008). Validity and reliability of the job content questionnaire in formal and informal jobs in Brazil. SJWEH Suppl, Scandinavian Journal of Work, Environment Eु Health; Journal information, 6, 52-59.

Araújo, T. M., \& Karasek, R. (2003) Estresse ocupacional e saúde: contribuições do Modelo Demanda-Controle. Ciência Ë Saúde Coletiva, 8,991-1003.(4).

Barbosa, O., Mello, A., \& Pereira, E. F. (2010). Confiabilidade (teste-reteste) da escala sueca do Questionário Demanda - Controle entre trabalhadores de Restaurantes Industriais do Estado do Rio de Janeiro. Rev. bras. epidemiol, 13(2), 212-222.

Brasil. (1998). Ministério da Educação e do Desporto. Secretaria da Educação Fundamental. Referencial Curricular Nacional para a Educação Infantil. Brasília: MEC/SEF.

Carloto, S. M. (2004). A Síndrome do burnout e o trabalho docente. Psicologia em Estudo, 7(1), 21-29.

Delcor, N. S, Araújo, T., Porto, L. A., Carvalho, F. M., Oliveira, M.,... Andrade, J. M. (2004). Condições de trabalho e saúde dos professores da rede particular de ensino de Vitória da Conquista, Bahia, Brasil. Cadernos de Saúde Pública, 20(1), 187-196.

Esteve, J. S. (1999). O Mal-estar docente. Bauru: EDUSC.

Decreto n⿳⺈ 4003, de 8 de setembro de 1999. (1999). Dispõe sobre a criação das Escolas Municipais de Educação Infantil em substituição as Creches Municipais.

Decreto-lei no 3048, de 6 de maio de 1999. (1999). Republicado em 12 de maio de 1999.

Garcia, M. M. A., \& Anadon, S. B. (2009). Reforma educacional, intensificação e auto-intensificação do trabalho docente. Educação $\mathcal{B}$ Sociedade, 30(106), 63-85.

Garcia, M. M. A., Hypolito, A. M., \& Vieira, J. S. (2004). A identidade docente no campo educacional In: Anais do XII ENDIPE: Conhecimento local e conhecimento universal (pp. 3003-3018). Curitiba, PR.

Gasparini, S. M., Barreto, S. M., \& Assunção, A. (2006). Prevalência de transtornos mentais comuns em professores da rede municipal de Belo Horizonte, Minas Gerais, Brasil. Cadernos de Saúde Publica, 22 (12), 2679-2691.

Hypolito, A. M., Vieira, J., \& Garcia, M. M. (2002). Trabalho docente: formação e identidades, 271-283.

Karasek, R. (1979). Job demand, job decision latitude and mental strain: implications for job redesign. Admin. Sci Quar, $24,285-308$

Martins, M. F., Vieira, J. S., \& Bugs, V. R. (2013). Aspectos psicossociais do trabalho e associação com as doenças: um estudo com as professoras da educação infantil de uma cidade de porte médio. Anais do Vll encontro Brasileiro da Rede Estrado: trabalho Docente e Políticas de Responsabilização (p. 54). Espírito Santo: Rede Estrado.

Paschoalino, J. B. Q. (2009) O Professor desencantado: matizes do trabalho docente. Belo Horizonte: Armazém de Ideias.

Pereira, E. F., Teixeira, C. S., Santos, A., Lopes, A. S., \& Merino, E. A. (2009). Qualidade de vida e saúde dos professores de educação básica: discussão do tema e revisão de investigações. Rev. bras. Ci e Mov, 17(2), 100-107.

Resolução CEB no 01/2003, de 20 de agosto de 2003. Dispõe sobre os direitos dos profissionais da educação com formação em nível médio, na modalidade Normal, em relação à prerrogativa do exercício da docência, em vista do disposto na Lei n⿳⺈ 9394/96, e dá outras providências.

Venzke, L. H. D. (2004). Professoras das escolas municipais de educação infantil de Pelotas: identidades em construção (Tese de Doutorado). Pelotas: UFPel.

Vieira, J. S. (2004). Um negócio chamado educação: qualidade total, trabalho docente e identidade. Pelotas: Seiva.

Vieira, J., Garcia, M. M., \& Martins, M. F. (2010). A constituição das doenças da docência. Cadernos de Educação (UFPel), 37, 303-324.

Vieira, J., Martins, \& M. F. (2012). Trabalho Docente: tensões e perspectivas (1a ed.). Maceió: EDUFAL.

\section{Endereço para correspondência}

